\title{
CONHECIMENTO DE MULHERES ACERCA DO PAPILOMAVÍRUS HUMANO E SUA RELAÇÃO COM O CÂNCER DE COLO UTERINO
}

\author{
Marisa de Castro Araújo França', Michelle de Castro Sampaio França1 ${ }^{1}$, Samara Dourado dos Santos Moraes ${ }^{2}$
}

\begin{abstract}
RESUMO: Este estudo teve como objetivo verificar o conhecimento de mulheres acerca do papilomavírus humano e sua relação com o câncer de colo uterino, forma de transmissão, prevenção, diagnóstico e tratamento. Trata-se de um estudo exploratório, descritivo de abordagem quantitativa realizado em Centro de Saúde de Teresina Piaú, com 126 mulheres, em 2012. Observou-se que 71,4\% conhecem o papilomavírus humano, mas 63,5\% desconhecem sua forma de transmissão e prevenção e 89,7\% desconhecem o que este provoca no organismo; $96,8 \%$ das entrevistadas referiram conhecer o câncer do colo do útero, mas $88,9 \%$ não sabem qual a relação deste com o papilomavírus humano. Conclui-se que há deficiência no conhecimento dessas mulheres sobre o papilomavírus humano, sua forma de prevenção, transmissão e sua relação com o câncer cervical. DESCRITORES: Infecções por papilomavírus; Saúde da mulher; Enfermagem.

\section{WOMEN'S KNOWLEDGE OF THE HUMAN PAPILLOMA VIRUS AND ITS RELATIONSHIP WITH CERVICAL CANCER}

\begin{abstract}
This study aimed to ascertain women's knowledge regarding the human papilloma virus and its relationship with cervical cancer, how it is transmitted, and its prevention, diagnosis and treatment. This is an exploratory, descriptive study with a quantitative approach, undertaken in a health center in Teresina in the state of Piauí, with 126 women, in 2012. It was observed that $71.4 \%$ know about the human papilloma virus, but that $63.5 \%$ are unaware of how it is transmitted or prevented, and that $89.7 \%$ are unaware of what it provokes in the organism; $96.8 \%$ of the interviewees stated that they knew about cervical cancer, but $88.9 \%$ do not know what relationship this has with the human papilloma virus. It is concluded that there are shortcomings in these women's knowledge about the human papilloma virus, how it is prevented and transmitted, and what its relationship is with cervical cancer. DESCRIPTORS: Infections from papilloma virus; Women's health; Nursing.
\end{abstract}

\section{CONOCIMIENTO DE MUJERES ACERCA DEL PAPILOMA VIRUS HUMANO Y SU RELACIÓN CON EL CÁNCER DE CUELLO DE ÚTERO}

RESUMEN: Este estudio tuvo el objetivo de verificar el conocimiento de mujeres acerca del papilomavírus humano y su relación con el cáncer de cuello de útero, forma de transmisión, prevención diagnóstico y tratamiento. Es un estudio exploratorio, descriptivo de abordaje cuantitativo realizado en Centro de Salud de Teresina, Piauí, con 126 mujeres, en 2012. Se observó que 71,4\% conocen el papiloma virus humano, pero 63,5 \% desconocen su forma de transmisión y prevención y $89,7 \%$ desconocen lo que este provoca en el organismo; $96,8 \%$ de las entrevistadas afirmaron conocer el cáncer de cuello de útero, pero $88,9 \%$ no saben su relación con el papiloma virus humano. Se concluye que hay deficiencia en el conocimiento de esas mujeres sobre el papiloma virus humano, su forma de prevención, transmisión y su relación con el cáncer cervical. DESCRIPTORES: Infecciones por papiloma virus; Salud de la mujer; Enfermería.

${ }^{1}$ Enfermeira.

${ }^{2}$ Enfermeira do Hospital Universitário da Universidade Federal do Piauí e da Maternidade Dona Evangelina Rosa. Mestre em Enfermagem. Professora da Faculdade Santo Agostinho. 


\section{INTRODUÇÃO}

As neoplasias constituem-se em um vasto e heterogêneo grupo de doenças que apresentam crescimento desordenado (maligno) de células que invadem os tecidos e órgãos, podendo expandir-se para outras regiões do corpo. Apesar dos avanços científicos sobre o câncer, que possibilitam prevenir e controlar as condições que provocam a doença, ainda prevalece alta incidência de cânceres, dentre eles o de colo uterino, principalmente nas populações de mulheres menos favorecidas $^{(1)}$.

O câncer de colo uterino é o terceiro tipo de tumor mais frequente na população feminina, e é classificado como a quarta causa de morte de mulheres por câncer no Brasil. De acordo com o Instituto Nacional do Câncer, com aproximadamente 17.540 novos casos por ano, o câncer de colo uterino foi responsável pelo óbito de 5.063 mulheres no Brasil em 2009. Uma análise regional no Brasil destaca o este câncer com incidência de 28/100 mil na região Centro-Oeste, 24/100 mil na região Norte. Na região Nordeste 18/100 mil, Sudeste 15/100 mil e região Sul $14 / 100 \mathrm{mil}^{(2)}$.

Diversos são os fatores de risco relacionados ao desenvolvimento do câncer de colo uterino, dentre eles a multiplicidade de parceiros e a história de infecções sexualmente transmitidas (da mulher e de seu parceiro); idade precoce na primeira relação sexual, multiparidade, tabagismo, alimentação pobre em alguns micronutrientes, principalmente vitamina $C$, beta caroteno e folato; e o uso de anticoncepcionais; sendo o principal fator é a infecção pelo Papilomavírus humano ${ }^{(3)}$.

A Organização Mundial de Saúde reconhece, desde 1992, o Papilomavírus humano como o principal responsável pelo câncer do colo do útero e identificou os tipos 16 e 18 como os principais agentes etiológicos desse tipo de câncer; o tipo 16 é responsável por $50 \%$ dos casos, seguido pelo tipo 18 , responsável por $12 \%$. A relação do Papilomavírus humano e o câncer de colo uterino é cerca de 10 a 20 vezes maior do que a relação do tabagismo com o câncer de pulmão ${ }^{(3)}$.

A transmissão do Papilomavírus humano se dá por contato direto com o epitélio oral, vaginal ou anal. O contágio dos indivíduos que fazem sexo com parceiros contaminados é de grau relativamente alto, com $25 \%$ a $65 \%$ de probabilidade de contaminação ${ }^{(4)}$. A infecção decorrente pode ser responsável pelo desenvolvimento de lesões de alto grau de maligni- dade, em alguns casos. A evolução das neoplasias intraepiteliais para o câncer cervical depende, entre outras variáveis, do tipo de vírus, da carga viral, da persistência da infecção pelo Papilomavírus humano e do estado geral do hospedeiro ${ }^{(5)}$.

Grande parte da população em geral desconhece o Papilomavírus humano. Em uma amostra de 25 mulheres, observou-se desconhecimento de aspectos importantes da doença e até confusão com a Síndrome da Imunodeficiência Adquirida ${ }^{(6)}$. Neste contexto, determinar o grau de conhecimento da população é fundamental para a seleção de estratégias mais adequadas para o planejamento de intervenções efetivas. Somente é possível aplicar medidas eficazes de promoção da saúde, prevenção da doença e câncer de colo uterino, através do conhecimento real acerca dos mitos, crenças e informações da população em relação a esta doença e ao seu principal fator de risco - o Papilomavírus humano.

Assim, esta pesquisa, teve como objetivo verificar o conhecimento de mulheres acerca do Papilomavírus humano no que diz respeito à forma de transmissão, prevenção, diagnóstico, tratamento e sua relação com o câncer de colo uterino.

Realizar este estudo justifica-se pela importância da temática, pela epidemiologia do câncer cervical, representando grande problema de saúde pública. É fato conhecido que a mortalidade por câncer do colo do útero é evitável uma vez que seja feito o diagnóstico na fase inicial, com maior chance de tratamento e permitindo a cura da totalidade dos casos.

Sabe-se que a melhor estratégia de combate ao câncer está na prevenção. Na atuação de enfermagem em qualquer área da saúde, pública ou privada, de atenção individual ou coletiva é de fundamental importância o conhecimento científico da doença, desde suas formas de contágio até a sua evolução para o câncer. Esse conhecimento da doença proporciona ao enfermeiro a possibilidade de desenvolver ações de educação em saúde mais direcionadas e adequadas de prevenção e controle do câncer do colo de útero.

\section{MÉTODO}

Trata-se de um estudo exploratório, descritivo de corte transversal com abordagem quantitativa. Foi realizado em um Centro de Saúde de Teresina-Piauí, pertencente à Regional Sul de Saúde. A população objeto deste estudo foram mulheres que procuraram os serviços do Centro de Saúde no período março a abril 
de 2012.. A amostra do estudo foi não probabilística por método de conveniência; foram escolhidas as mulheres que atenderam aos critérios pré-estabelecidos. Como critérios de inclusão do estudo citam-se: faixa etária entre 25 a 64 anos, com condições de responder ao questionário sem prejuízo das respostas por motivos de deficiência auditiva ou comportamento coerente com doenças psiquiátricas.

Os dados desse estudo foram coletados através de entrevista com utilização de um questionário estruturado elaborado pelas autoras e validado por meio de entrevistas com usuárias de equipes da Estratégia Saúde da Família que não compuseram a amostra deste estudo. O questionário continha aspectos sociodemográficos e questões relacionadas ao conhecimento das mulheres a respeito do Papilomavírus humano e da sua relação com o câncer cervical bem como sua forma de prevenção.

Todas as mulheres que cumpriram os critérios de inclusão, após abordagem, foram convidadas a responder o questionário após a leitura e assinatura do Termo de Consentimento Livre e Esclarecido de acordo com a Resolução 196/96. Após a coleta, compôs-se um banco de dados, onde foram consolidados utilizando as técnicas de estatística descritiva (frequência absoluta, frequência percentual) e apresentados sob forma de tabelas. Os resultados dos dados foram processados no programa Statistical Product and Service Solutions, versão 18.0 e analisados descritivamente medindo-se a taxa de associação entre variáveis do estudo.

A discussão dos achados foi feita com base na literatura produzida sobre o tema. Este estudo foi aprovado pelo Comitê de Ética em Pesquisa da Faculdade NOVAFAPI, no dia 18/01/2012, CAAE 0380.0.043.000-11, bem como pela instituição onde foi realizado o estudo.

\section{RESULTADOS}

Participaram 126 mulheres e os dados apresentados na tabela 1 mostram que $71,4 \%$ das entrevistadas conheciam o vírus e referiram a televisão como o principal veículo de informação.

A respeito da forma de transmissão do Papilomavírus humano, a tabela 2 mostra que $63,5 \%$ das entrevistadas não sabiam como ocorre a transmissão do vírus. Quanto a forma de prevenção $63,5 \%$ das mulheres referiram não conhecer como prevenir-se do Papilomavírus humano.
A tabela 3 mostra que a maioria das mulheres $(89,7 \%)$ relataram não conhecer os sintomas do $\mathrm{Pa}-$ pilomavírus em uma pessoa, nem o que este causa ao organismo.

A respeito do conhecimento sobre o câncer de colo uterino, observou-se que $96,8 \%$ das mulheres conheciam esse tipo de câncer; no que tange a sua relação com o Papilomavírus humano, sua cura e a realização do exame Papanicolaou, os resultlados foram agrupados na tabela 4 .

Os dados mostram que entre todas as mulheres entrevistadas, $88,9 \%$ não sabiam a relação existente entre o Papilomavírus humano e o câncer cervical. Ao serem questionadas sobre a cura do Papilomavírus humano, 58,7\% relataram que não haver cura. Acerca da cura do câncer de colo de útero, observou-se que a maioria das mulheres $(72,2 \%)$ afirma há cura. A respeito da realização do exame Papanicolaou, $75,4 \%$ afirmaram já ter realizado.

Tabela 1 - Distribuição da frequência das mulheres, segundo conhecimento do Papilomavírus humano e as fontes de obtenção desse conhecimento. Teresina, 2012

\begin{tabular}{lcc}
\hline VARIÁVEIS & n & \% \\
\hline Conhece o Papilomavírus humano & \\
Sim & 90 & 71,4 \\
Não & 36 & 28,6 \\
Total & 126 & 100,0 \\
Fontes de obtenção de conhecimento do Papilo- \\
mavírus humano & \\
Televisão & 43,6 \\
Profissionais de saúde & 34,9 \\
Outras & 29,7 \\
Total & $108,2^{*}$ \\
\hline *Som
\end{tabular}

*Soma mais de $100 \%$, pode haver mais de um item preenchido.

Tabela 2 - Distribuição da frequência das mulheres, segundo as Formas de transmissão e de Prevenção do Papilomavírus humano. Teresina, 2012

\begin{tabular}{lcc}
\hline VARIÁVEIS & n & \% \\
\hline \multicolumn{2}{l}{ Forma de transmissão do } & Papilomavírus humano \\
Relação sexual & 44 & 34,9 \\
Pelo beijo & 2 & 1,6 \\
Não sabe & 80 & 63,5 \\
Total & 126 & 100,0 \\
Forma de prevenção do Papilomavírus humano \\
Usando camisinha & 44 & 34,9 \\
Não beijar pessoas doentes & 2 & 1,6 \\
Não sabe & 80 & 63,5 \\
Total & 126 & 100,0 \\
\hline
\end{tabular}


Tabela 3 - Distribuição da frequência das mulheres, segundo conhecimento sobre os sintomas do Papilomavírus humano e o que este causa ao organismo. Teresina, 2012

\begin{tabular}{lcc}
\hline VARIÁVEIS & $\mathbf{n}$ & $\mathbf{\%}$ \\
\hline Conhece os sintomas do Papilomavírus humano & 13 & 10,3 \\
Sim & 113 & 89,7 \\
Não & 126 & 100,0 \\
Total & \\
O que o Papilomavírus humano causa & \\
Somente câncer de colo de útero & 12 & 9,5 \\
Verrugas na genitália e/ou & 1 & 0,8 \\
câncer de colo do útero & 113 & 89,7 \\
Não sabe & 126 & 100,0 \\
Total & & \\
\hline
\end{tabular}

Tabela 4 - Distribuição da frequência das mulheres, segundo informações sobre câncer de colo uterino, Papilomavírus humano e realização do exame Papanicolaou. Teresina, 2012

\begin{tabular}{lcc}
\hline VARIÁVEIS & n & \% \\
\hline $\begin{array}{l}\text { Relação entre Papilomavírus humano e câncer de } \\
\text { colo de útero }\end{array}$ & & \\
Causa o câncer de colo uterino & 12 & 9,5 \\
Não tem relação com o câncer de & 2 & 1,6 \\
colo uterino & 112 & 88,9 \\
Não sabe & 126 & 100,0 \\
Total & 52 & 41,3 \\
O Papilomavírus humano tem cura & \\
Sim & 74 & 58,7 \\
Não & 126 & 100,0 \\
Total & & \\
O câncer de colo uterino tem cura & 91 & 72,2 \\
Sim & 35 & 27,8 \\
Não & 126 & 100,0 \\
Total & & \\
Realizou o exame Papanicolaou & 95 & 75,4 \\
Sim & 31 & 24,6 \\
Não & 126 & 100,0 \\
\hline Total & & \\
\hline
\end{tabular}

DISCUSSÃO

Constatou-se que a maioria das entrevistadas conhece o Papilomavírus humano, em concordância com os resultados obtidos em outra pesquisa envolvendo mulheres na faixa etária de 40 a 60 anos, na qual 87,7\% das participantes revelaram conhecimento sobre o vírus $^{(7)}$. Nos entanto, esses dois achados diferem do resultado obtido em um estudo que teve como objetivo avaliar a aplicabilidade de uma cartilha educativa para a promoção e prevenção de infecções e neoplasias oca- sionadas pelo Papilomavírus humano e no qual a maioria $(64,5 \%)$ da população analisada não apresentava conhecimento prévio sobre o Papilomavírus humano ${ }^{(8)}$.

A televisão foi o principal veículo para a informação nesta pesquisa $(43,6 \%)$ e também em outro estudo realizado, citada por $46,7 \%$ das entrevistadas ${ }^{(7)}$. Isso mostra certa deficiência das equipes de saúde em promover a educação em saúde. É importante que os profissionais responsáveis por tal ação durante $\mathrm{o}$ atendimento à mulher, focalizem não somente na realização do exame em si, mas também ativando seu papel de educador em saúde no momento da consulta. Em contrapartida, noutro estudo, constatou-se que a maioria tinha conhecimento e que as fontes deste eram os serviços de saúde ${ }^{(9)}$.

A respeito da forma de transmissão do Papilomavírus humano, $63,5 \%$ das entrevistadas não sabiam como essa ocorre. Quanto a forma de prevenção $63,5 \%$ das mulheres referiram não saber como se prevenir do Papilomavírus humano. Esses achados diferem de outra pesquisa que constatou que $60 \%$ das entrevistadas conheciam a forma de transmissão, caracterizada por meio da relação sexual, e 53,3\% conheciam sua prevenção por meio do uso de preservativos ${ }^{(7)}$.

Apesar das iniciativas em termos de políticas de saúde voltadas à saúde da mulher, como as campanhas de conscientização e divulgação para realização do Papanicolaou, com acesso facilitado e gratuito, considera-se que grande parte da população feminina tem conhecimento sobre Papilomavírus humano, mas desconhecem as formas de transmissão, prevenção e sintomas $^{(10)}$. Fica, então, evidenciada a importância das atividades de educação em saúde. Tais ações devem visar a divulgação de informações sobre o vírus, bem como a mobilização da população-alvo a buscar os benefícios oferecidos pelos programas de rastreamento.

As mulheres reconhecem o uso do preservativo como a melhor estratégia de prevenção, porém, elas consideram o preservativo um elemento incômodo no qual dificulta a vivência da sexualidade do casal. Lembrando que, apesar de o preservativo ser indicado para prevenir infecções causadas por Papilomavírus humano e Síndrome da Imunodeficiência Adquirida, bem como outras doenças sexualmente transmissíveis, esta medida não evita a contaminação pelo Papilomavírus humano em todos os casos. Qualquer contato pele a pele com o condiloma pode transmitir o vírus ${ }^{(7)}$.

Neste estudo observou-se que a maioria das mulheres $(89,7 \%)$ relatou não saber os sintomas do Papilomavírus em uma pessoa nem o que este causa ao 
organismo. Em outra pesquisa, também se observou que a população do estudo desconhecia o Papilomavírus humano como principal agente oncogênico ${ }^{(10)}$.

A respeito do conhecimento sobre o câncer de colo uterino, $96,8 \%$ das mulheres desta pesquisa conheciam esse tipo de câncer. O câncer de colo uterino é mais conhecido pela população em virtude de existirem políticas e programas de saúde voltados diretamente para rastreiamento e tratamento precoce ${ }^{(11)}$.

Observa-se que entre todas as mulheres entrevistadas $88,9 \%$ não sabiam a relação que existe entre o Papilomavírus humano e o câncer de colo uterino. Esses achados concordam com outra pesquisa, já que $64,5 \%$ das entrevistadas também não conheciam a relação existente $^{(8)}$. Assim, reitera-se que a educação é fundamental para combater a desinformação, sendo única em sua condição de esclarecer dúvidas e desfazer conceitos errôneos.

Ao serem questionadas sobre a cura do Papilomavírus humano, 58,7\% relataram que não há cura. Esse resultado vai ao encontro de estudo que constatou que a maioria das mulheres $(46,7 \%)$ não acreditava na possibilidade de cura do Papilomavírus humano ${ }^{(9)}$. Até recentemente, acreditava-se que não existia cura para o Papilomavírus humano, apenas tratamento. Entretanto, para alguns tipos prevalentes deste vírus, existe a cura desde que diagnosticado precocemente.

Acerca da cura do câncer de colo de útero, $72,2 \%$ das mulheres afirmam que há cura. É fato que a mortalidade por câncer do colo do útero é evitável, uma vez que as ações para seu controle contam com tecnologias para o diagnóstico e tratamento de lesões precursoras, permitindo a cura em $100 \%$ dos casos diagnosticados na fase inicial ${ }^{(12)}$.

A respeito da realização do exame Papanicolaou, $75,4 \%$ afirmaram já ter realizado. Este resultado concorda com este estudo onde $96,7 \%$ das entrevistadas já haviam realizado exame preventivo em algum momento de sua vida ${ }^{(7)}$. O exame preventivo do câncer do colo do útero, o Papanicolaou, é a principal estratégia para detectar lesões precursoras e fazer o diagnóstico da doença. O Ministério da Saúde recomenda este exame a toda mulher com idade entre 25 e 64 anos e que possua vida sexual ativa. Inicialmente, o exame deve ser feito a cada três anos. Em caso de dois resultados negativos para displasia ou neoplasia, um novo exame deverá ser repetido uma vez a cada três anos ${ }^{(2)}$.

Para a estruturação do rastreamento organizado de base populacional, as ferramentas de informação, $o$ modelo de financiamento e as práticas de convocação e registro de mulheres atualmente disponíveis ainda são insuficientes. Faz-se necessário adaptar as estratégias dos programas de educação em saúde às características regionais onde o mesmo será implementado ${ }^{(2)}$.

\section{CONCLUSÃO}

Pode-se constatar que apesar das mulheres conhecerem o Papilomavírus humano, o câncer do colo do útero e realizarem o exame de prevenção, elas não têm conhecimento adequado e suficiente para se prevenir da contaminação e se tratar corretamente para impedir que a contaminação pelo Papilomavírus humano evolua para o câncer cervical. Elas sabem que têm que realizar o exame de prevenção mas não têm conhecimento do porquê.

Portanto, concluiu-se a partir dos dados deste estudo, que se faz necessário a implementação de programas educativos e assistenciais nesta faixa etária, principalmente pelo fato de a idade apresentar-se como fator de risco para o câncer de colo uterino. Também é importante sensibilizar os profissionais da saúde, em especial os enfermeiros, para a intensificação de ações educativas, capazes de oferecer informações completas e de fácil entendimento sobre o Papilomavírus humano e sua relação com o desenvolvimento câncer do colo do útero de forma que influencie a população feminina a estarem buscando periodicamente a realização do Papanicolaou.

De uma maneira geral, para os programas de educação em saúde e de rastreamento precoce terem sucesso é necessário haver cobertura mais efetiva da população de risco, treinamento específico para os profissionais de saúde capaz de torná-los aptos a fornecerem todas as informações a respeito do Papilomavírus humano e do câncer do colo uterino para depois realizar o Papanicolaou com as mulheres esclarecidas; boa qualidade, tanto na coleta quanto na interpretação do material, tratamento e acompanhamento adequados.

\section{REFERÊNCIAS}

1. Veras JMMF. Vivências de mulheres com câncer de colo uterino: implicações para a enfermagem. 2011[dissertação]. Programa de Pós Graduação em Enfermagem. Teresina (PI): Universidade Federal do Piauí. Disponível: http://www.ufpi.br/mestenfermagem/ index/pagina/id/4620.

2. Ministério da Saúde(BR). Instituto Nacional de Câncer (INCA). Estimativa 2012-Incidência de câncer no Brasil, Rio de Janeiro: INCA; 2011 [Internet] [acesso 
em 01 mai 2012]. Disponível: http://wwwl.inca.gov.br/ estimativa/2012/index.asp?ID=5.

3. Ministério da Saúde (BR). Falando sobre o câncer do colo do útero, Rio de Janeiro: MS/ INCA; 2002 [Internet] [acesso em 04 set 2011]. Disponível: http:// www.linca.gov.br/publicacoes/inca/falando_cancer_ colo_utero.pdf.

4. Bertolin DC, Ribeiro RCHM, Cesarino CB. Conhecimento de mulheres que fazem sexo com mulheres sobre o papilomavirus humano. Cogitare enferm. [Internet] 2010:15(4) [acesso em 04 set 2011]. Disponível: http://ojs.c3sl.ufpr.br/ojs2/index.php/ cogitare/article/view/20377

5. Santana E, Biselli PM, Biselli JM, Almeida MTG, Bertelli ECP. Câncer Cervical: etiologia, diagnóstico e prevenção. Cienc. saude. [Internet] 2008;15(4) [acesso em 07 set 2011]. Disponível: http://www.cienciasdasaude. famerp.br/racs_ol/vol-15-4/IDB\%20304.pdf.

6. Diógenes MAR, Varela ZMV, Barroso GT. Papillomavirus humano: repercussão na saúde da mulher no contexto familiar. Rev. Gaúcha Enferm. [Internet] 2006;27(2) [acesso em 05 set 2011]. Disponível: http:// seer.ufrgs.br/RevistaGauchadeEnfermagem/article/ view/4605.

7. Silveira CF, Melo MM, Rodrigues LR, Parreira BDM. Conhecimento de mulheres de 40 a 60 anos sobre o Papilomavírus humano. Rev. Rene. [Internet] 2011;12(2) [acesso em 05 set 2011]. Disponível: http:// www.revistarene.ufc.br/revista/index.php/revista/ article/view/158/69

8. Reis AAS, Monteiro CD, Paula LB, Santos RS, Saddi RA, Cruz AD. Papilomavírus humano e saúde pública: prevenção ao carcinoma de cérvice uterina. Ciênc. saúde colet. [Internet] 2010;15(1) [acesso em 04 jun 2012]. Disponível: http://dx.doi.org/10.1590/S141381232010000700012 .

9. Souza LB, Pinheiro AKB, Barroso MGT. Ser mulher portadora do HPV: uma abordagem cultural. Rev Esc Enferm USP. [Internet] 2012;42(4) [acesso em 04 jun 2012]. Disponível: http://dx.doi.org/10.1590/S008062342008000400017

10. Cirino FMSB, Nichiata LYI, Borges ALV. Conhecimento, atitudes e práticas na prevenção do câncer de colo uterino e HPV em adolescentes. Esc. Anna Nery.[Internet] 2010;14(1) [acesso em 04 jun 2012]. Disponível: http://dx.doi.org/10.1590/S141481452010000100019
11. Bastos EA. Estimativa da efetividade do programa de rastreamento do câncer do colo do útero no estado do Rio de Janeiro [dissertação]. Programa de Pós Graduação em Engenharia Biomédica. Rio de Janeiro (RJ): Universidade Federal do Rio de Janeiro; 2011. Disponível: http://www.peb.ufrj.br/noticias/2011-0812-DefesaEdiane.pdf.

12. Cesarin MR, Piccoli JCE. Educação em saúde para prevenção do câncer de colo do útero em mulheres do município de Santo Ângelo-RS. Ciênc. saúde colet.[Internet] 2011;16(09) [acesso em 14 jun 2012]. Disponível: http://dx.doi.org/10.1590/S141381232011001000029

Cogitare Enferm. 2013 Jul/Set; 18(3):509-14 